\title{
MAX PLANCK
}

\section{IN SEINEN AKADEMIE-ANSPRACHEN}

\author{
ERINNERUNGSSCHRIFT \\ DER DEUTSGHEN AKADEMIE \\ DER WISSENSCHAFTEN ZU BERLIN
}

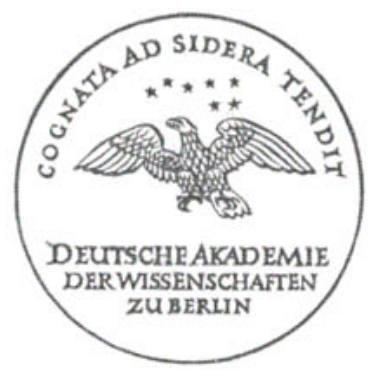

1948

AKADEMIE-VERLAG • BERLIN 


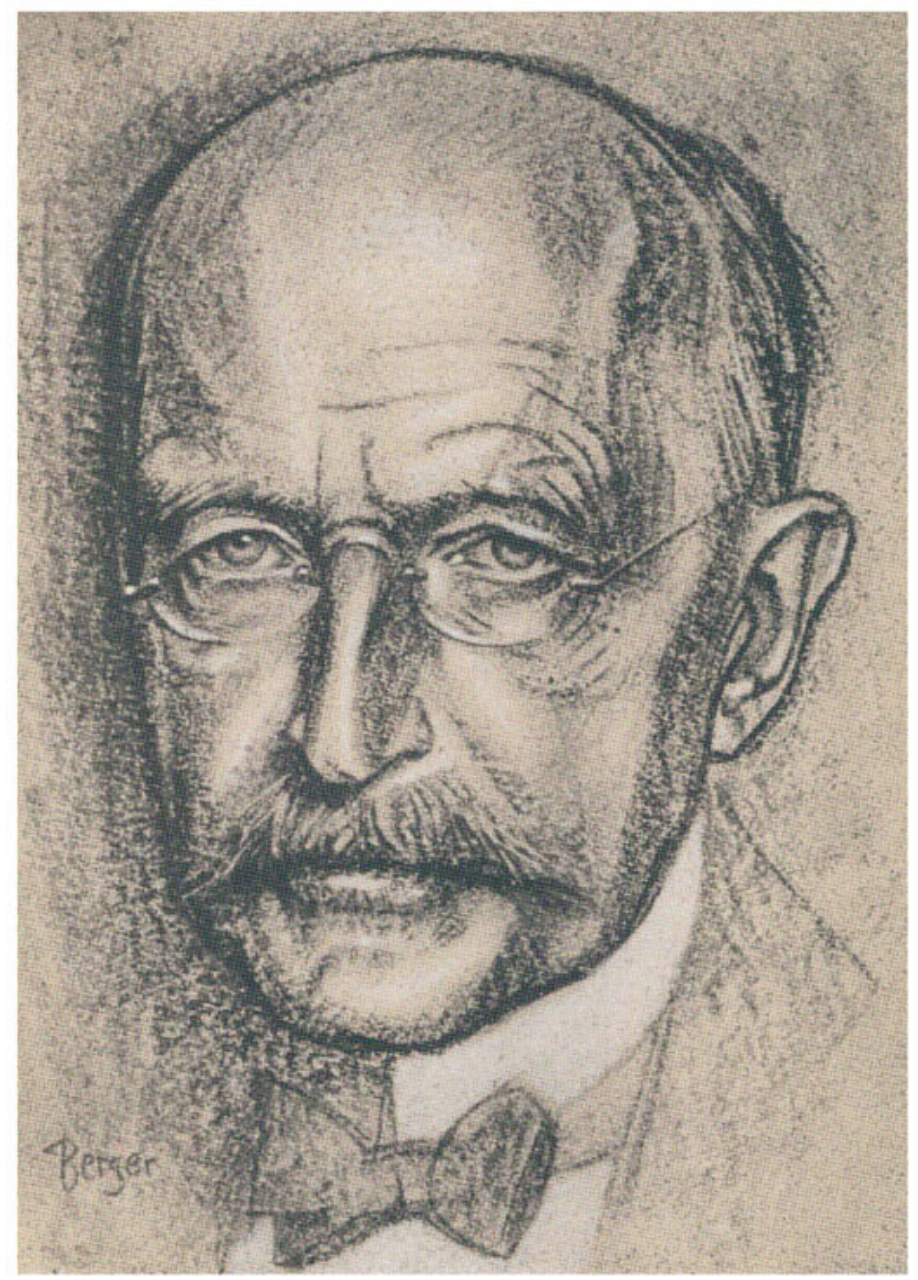

hax 9eanch 


\title{
MAX PLANCK
}

\section{IN SEINEN AKADEMIE-ANSPRACHEN}

\author{
ERINNERUNGSSCHRIFT \\ DER DEUTSCHEN AKADEMIE \\ DER WISSENSCHAFTEN ZU BERLIN
}

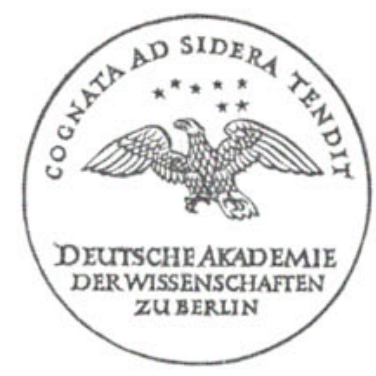

1948

AKADEMIE-VERLAG - BERLIN 
Erschienen im Akademie.Verlag GmbH., Berlin NW 7, Schiffbauerdamm 19 Lizenz-Nr.156 - 2862/48 - 3363/48

Druck ISD N r.945/10354 Staatsdrudkerei, BerlinSW 68, Kommandantenstr. 7.9 Bestell. und Verlagsnummer 5015 
DIESE ERINNERUNGSSCHRIFT WURDE ANLÅSLICH DER GEDENKFEIER FÜR MAX P LAN C K

Ordentliches Mitglied der Akademie von 1894-1947

Beständiger Sekretar der mathemat.-națurwissensch.Klasse von 1912-1938

AM LEIBNIZTAGE DER AKADEMIE

DEM 1. JULI 1948, VORGELEGT

VON DER

DEUTSCHEN AKADEMIE DER WISSENSCHAFTEN

ZU BERLIN 
